\title{
Maternal socio-economic disadvantage in Aotearoa New Zealand and the impact on midwifery care
}

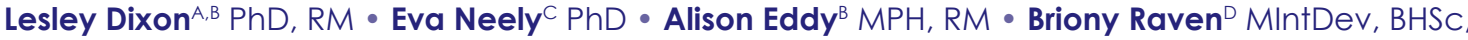
BA - Carol Bartle ${ }^{B}$ MHealSc, PGDip, ChAd, RM, RN

${ }^{\mathrm{A}}$ Corresponding Author: practice@ nzcom.org.nz

${ }^{B}$ New Zealand College of Midwives, New Zealand

${ }^{\mathrm{C}}$ Victoria University of Wellington, New Zealand

D Maternity Equity Action, New Zealand

\section{ABSTRACT}

Background: Maternal socio-economic disadvantage affects the short- and long-term health of women and their babies, with pregnancy being a particularly vulnerable time.

Aim: The aim of this study was to identify the key factors that relate to poverty for women during pregnancy and childbirth (as identified by midwives), the effects on women during maternity care and the subsequent impact on the midwives providing that care.

Method: Survey methodology was used to identify Aotearoa New Zealand midwives' experiences of working with women living with socio-economic disadvantage.

Findings: A total of 436 midwives (16.3\%) who were members of the New Zealand College of Midwives responded to the survey, with $55 \%$ working in the community as Lead Maternity Care midwives, or caseloading midwives, and the remainder mostly working in maternity facilities.

The survey results found that $70 \%$ of the cohort of midwives had worked with women living with whānau (family) /friends; 69\% with women who had moved house during pregnancy due to the unaffordability of housing; $66 \%$ with women who lived in overcrowded homes; and $56.6 \%$ with women who lived in emergency housing, in garages $(31.6 \%)$, in cars $(16.5 \%)$ or on the streets (11\%). The cohort of midwives identified that women's non-attendance of appointments was due to lack of transport and lack of money for phones, resulting in a limited ability to communicate. In these circumstances these midwives reported going to women's homes to provide midwifery care to optimise the chances of making contact. The midwives reported needing to spend more time than usual referring and liaising with other services and agencies, to ensure that the woman and her baby/ family had the necessities of life and health.

This cohort of midwives identified that women's insufficient income meant that midwives needed to find ways to support them to access prescriptions and transport for hospital appointments. The midwives also indicated there was a range of social issues, such as family violence, drugs, alcohol, and care and protection concerns, that directly affected their work.

Conclusion: Recognising the impact of socio-economic disadvantage on maternal health and wellbeing is important to improving both maternal and child health. This cohort of midwives identified that they are frequently working with women living with disadvantage; they see the reality of women's lives and the difficulties and issues they may face in relation to accessing physical and social support during childbirth.

Keywords: midwifery, socio-economic disadvantage, maternity care

\section{INTRODUCTION}

Maternal socio-economic disadvantage in the perinatal period is an important predictor of long-term outcomes, including health, education, income and adverse early life experiences

(Asher \& St John, 2016; Braveman, Cubbin, Egerter, Williams, \& Pamuk, 2010; Clark, D'Ambrosio, \& Barazetta, 2019; Larson, 2007; Vettore, Gama, Lamarca, Schilithz, \& Leal, 2010). Widening health disparities are impacting on women's wellbeing, as well as affecting the ways in which midwives can deliver quality care. In Aotearoa New Zealand midwives work closely with women and their whānau (families) to develop a partnership relationship. This relationship supports an improved understanding of the issues women face in relation to socio-economic disadvantage and how it affects the woman's maternity care.

\section{Effects of socio-economic disadvantage on pregnant women}

Socio-economic disadvantage during pregnancy has an impact on maternal health, pregnancy outcome and child health, and can have a growing effect for families through the context of cumulative 
exposure from one generation to the next. Pregnant women with low incomes are more likely to experience negative life events, stress, depression and family violence during pregnancy (Best start: Ontario's Maternal Newborn and Early Child Development Resource Centre, 2003; Katz, Crean, Cerulli, \& Poleshuck, 2018; Phelan, DiBenedetto, Paul, Zhu, \& Kjerulff, 2015). They are less likely to access early maternity care and often feel powerless and have low self-esteem (Best start: Ontario's Maternal Newborn and Early Child Development Resource Centre, n.d.; McLeish $\&$ Redshaw, 2019). Women and their babies in lower socioeconomic groups are over represented in mortality statistics with higher maternal mortality and perinatal mortality, i.e. stillbirth and neonatal death (Perinatal and Maternal Mortality Review Committee, 2019). In Aotearoa New Zealand 22.3\% of women who gave birth in 2017 lived in the most deprived quintiles and were more likely to be multiparous, have a high BMI, smoke during pregnancy and book for pregnancy care later (Ministry of Health, 2019). They were also more likely to have a pre-term birth, a low birthweight baby and were less likely to breastfeed. Those living in the most deprived neighbourhood (quintile 5) include $48.5 \%$ of Māori, $58.8 \%$ of Pasifika and $31.9 \%$ of Indian women, compared to $14 \%$ of NZ European.

Children depend on their parents and families for meeting their basic needs, yet for those parents/families experiencing financial hardship, many are unable to meet these needs. It is estimated that $14-15 \%$ of children in Aotearoa New Zealand live with socio-economic disadvantage, dependent on the measure used to determine poverty (Department of the Prime Minister and Cabinet, 2018). Children living in the most deprived regions experience poorer social and emotional health and exhibit more behavioural difficulties (Ministry of Health, 2018). Maternal stress during pregnancy can also affect the ongoing health of the child. Kingsbury et al. (2016) found an association with depression during adolescence following high levels of maternal antenatal stressful life events. The wellbeing of children is now a government priority in Aotearoa New Zealand and the Child Poverty Reduction Act introduced in 2018 aims at achieving a significant and sustained reduction in child poverty (Department of the Prime Minister and Cabinet, 2018; Stats NZ, 2019). It could be argued that the genesis of child poverty is maternal and/or family poverty, which is frequently caused and exacerbated during pregnancy and following childbirth in families who have increased vulnerability (Larson, 2007). Socio-economic disadvantage is often intergenerational, with environmental conditions exerting a strong influence on short- and long-term outcomes for both the mother and her children (Braveman et al., 2010; Clark et al., 2019). The midwifery perspective on care provision for women living with socio-economic deprivation has not been widely explored in Aotearoa New Zealand. One author (Griffiths, 2002) has described the experiences of eight Aotearoa New Zealand midwives providing midwifery care to women living in socioeconomic deprivation. These midwives identified the importance of being even more closely involved due to the women's needs and a desire to optimise pregnancy outcomes. Priday (2018) reviewed engagement with pregnancy care of eight women living in a socio-economically deprived community. She reported that these women found accessing midwifery care daunting and required supportive navigation into maternity care. Recognising the impact of socio-economic disadvantage on maternal health and wellbeing is important to improving both maternal and child health and is integral to ensuring a reduction in child poverty.

The aim of this study was to identify the prevalence of key factors that relate to socio-economic disadvantage for women during pregnancy and childbirth, the impact on women during their maternity care and the impact on the midwives providing that care.

\section{METHOD}

This research used a single cross sectional study design involving survey methodology. A survey tool was developed which aimed to identify indicators of socio-economic disadvantage and explore the impact on maternity care.

\section{Development of the survey tool - indicators of socio-economic disadvantage}

Statistics NZ have developed a measurement tool known as DEP 17 as a way of measuring material hardship for children in Aotearoa New Zealand to ensure consistency of measurement for their purposes (Stats NZ, 2019). However, this study was not surveying individual women so we were unable to use DEP 17 . Instead we reviewed common themes found in the literature related to socio-economic disadvantage and which we posited could affect pregnant women. These were: housing and homelessness (Kelly et al., 2013), heating, mould and weatherproofing (Fisk, Eliseeva, \& Mendell, 2010; Grey, Schmieder-Gaite, Jiang, Nascimento, \& Poortinga, 2017), income and food insufficiency (Carter, Kruse, Blakely, \& Collings, 2011; Moafi, Kazemi, Samiei Siboni, \& Alimoradi, 2018; van den Heuvel \& Birken, 2018) and social issues such as smoking, drugs and alcohol (Foster et al., 2018).

The research team developed the themes from the literature to establish four quasi-indicators of socio-economic disadvantage which collectively would indicate socio-economic disadvantage and how it could be identified by midwives. These were:

\section{Housing and homelessness}

2. Heating and weatherproofing of homes

3. Income and food insecurity

4. Social issues such as family violence, drugs, alcohol and care and protection concerns.

Survey questions for each quasi-indicator were developed to gain an understanding of the prevalence of maternal socio-economic disadvantage and its impact on maternity care. The survey questions included four which were specifically asking about housing, heating/weatherproofing, income/ food security and social issues.

Questions were set out with multiple answer responses, with additional questions asking how these issues impacted on midwifery care. Respondents were provided with a range of options that covered concepts of time, access, emotional impact and safety. Participants were given an opportunity to write a free text response as a means of providing further detail to their answers and further explain the complexities and impact of socio-economic disadvantage. Demographic information questions regarding the midwife's role, district health board region and caseload size were included. Ethnicity data were not collected from the midwifery respondents nor was it possible to identify the ethnicity of the women they were discussing in their responses.

A final question asked the respondents to share a clinical example from a time during the last year concerning a woman they were caring for who was living with socio-economic disadvantage. Skip logic was used to ensure that the questions suited the work setting identified by the midwife respondent (hospital or community). 
The survey was piloted by three midwives who reported the questions were clear, concise and easy to answer.

\section{Participants}

The survey was hosted on the SurveyMonkey® website and access to the survey was provided by the New Zealand College of Midwives (the College) to all midwife members via an email link on 6th December 2018, with a reminder a week later. The survey was closed on 20th December 2018

\section{Ethics}

The project was evaluated by peer review through the Massey University Ethics Committee and identified as low risk (Ethics identification number 4000020305).

\section{Methods of analysis}

The survey responses were cleaned and analysed using SPSS version 25. Descriptive statistics were provided for the survey responses. Survey question responses are supported by comments from the respondents.

\section{FINDINGS}

\section{Demographics of the participants}

A total of 439 midwives (16.3\%) responded, of which 55.8\% were caseloading or Lead Maternity Care (LMC) midwives and 28.5\% were hospital (core) midwives (Table 1). The 38 respondents who identified their role as "other" specified roles such as researcher, locum, casual midwife, maternity manager, specialist midwife and midwife manager. The largest proportion of respondents was from the Auckland region (27.3\%) although each region of the College had respondents. Similarly, participants reported working within each of the 20 district health boards, with the highest proportion within the Canterbury District Health Board (10.9\%). The majority of midwifery respondents who had a caseload reported an average caseload size of between 41 and 60 women a year (17.8\%).

\section{Housing and homelessness}

One of the key questions we asked midwives was whether any women under their care had experienced issues related to housing and homelessness during the previous twelve months (Table 2). A high proportion of both hospital and caseloading midwives identified issues related to housing, with women staying with whānau/friends most commonly identified (70\%), followed by women moving addresses due to the unaffordability of housing (69.7\%). Furthermore, $66.1 \%$ identified overcrowded housing as being a concern, with $56.5 \%$ of midwives indicating they had provided care to women living in emergency housing at some point during their maternity care. Smaller proportions identified that women in their care had become homeless during pregnancy (46.2\%) or following the birth (20.4\%) and reported women living in a garage $(31.6 \%)$, in a car $(16.5 \%)$ or on the streets $(11 \%)$.

\section{Comments from midwives:}

(Woman's name) was accepted in a Motel for 3 weeks with her children and moved to Emergency accommodation with a charity agency for the rest of her pregnancy... She is now out of area for my DHB but I managed to continue to be her LMC as my team is very supportive of me and wish her to continue treatment of her medical condition and pregnancy in our DHB. Transport has been arranged. And, she has a fridge to keep her insulin safe.
I was caring for a woman readmitted at day 15 for an MRSA infection in her caesarean wound. She had a toddler and a newborn. When she initially was discharged from hospital she and her family were living in the car. During the period of her readmission she was able to obtain emergency housing in a motel. The impact of major surgery and hospital acquired infection in the context of extreme poverty was devastating for her and her family, and negatively impacted her personal wellbeing, breastfeeding, and ability to parent well.

\section{Table 1. Demographics of survey participants}

\begin{tabular}{|c|c|c|}
\hline Demographics of participants & $\mathbf{n}$ & $\%$ \\
\hline \multicolumn{3}{|l|}{ Work type } \\
\hline Core midwife in a tertiary unit & 50 & 11.4 \\
\hline Core midwife in a secondary unit & 46 & 10.5 \\
\hline Core midwife in a primary unit & 29 & 6.6 \\
\hline LMC or Caseloading midwife & 245 & 55.8 \\
\hline Educator/manager & 29 & 6.6 \\
\hline Other (please specify) & 38 & 8.7 \\
\hline Missing & 2 & 0.5 \\
\hline Total & 439 & 100 \\
\hline \multicolumn{3}{|l|}{ College region } \\
\hline Northland & 32 & 7.3 \\
\hline Auckland & 120 & 27.3 \\
\hline Waikato & 47 & 10.7 \\
\hline Bay of Plenty & 34 & 7.7 \\
\hline Central & 61 & 13.9 \\
\hline Wellington & 44 & 10.0 \\
\hline Nelson & 15 & 3.4 \\
\hline Canterbury/West Coast & 49 & 11.2 \\
\hline Otago & 27 & 6.2 \\
\hline Southland & 7 & 1.6 \\
\hline Missing & 3 & 0.7 \\
\hline Total & 439 & 100 \\
\hline \multicolumn{3}{|l|}{ Caseload size } \\
\hline Less than 10 & 4 & 0.9 \\
\hline 11 to 20 & 10 & 2.3 \\
\hline 21 to 40 & 52 & 11.8 \\
\hline 41 to 60 & 78 & 17.8 \\
\hline More than 60 & 49 & 11.2 \\
\hline Total* & 193 & 100 \\
\hline
\end{tabular}

*52 caseloading participants did not respond

\section{Heating and weatherproofing of homes}

The survey asked the 245 respondents who were community LMC or caseloading midwives, and who predominantly home visit during postnatal care, about the condition of women's homes and whether these were cold, damp or mouldy (Table 3). This question was not asked of the hospital midwives (or those in the "educator/manager" or "other" categories) because they do not usually visit the home when providing midwifery care.

Community midwives were also asked whether they considered the homes to have inadequate heating and cooking facilities and whether the home was weatherproof. Just under two thirds of the midwifery respondents $(62.9 \%)$ identified visiting homes withinadequate heating, with $57.1 \%$ stating that they had visited 


\begin{tabular}{|c|c|c|c|c|c|c|c|c|}
\hline \multirow{2}{*}{$\begin{array}{l}\text { Question: Have you provided care to women with issues with housing } \\
\text { over the last } 12 \text { months? } \\
\text { Housing issue }\end{array}$} & \multicolumn{2}{|c|}{$\begin{array}{l}\text { Caseloading } \\
\text { or LMC midwife } \\
(n=245)\end{array}$} & \multicolumn{2}{|c|}{$\begin{array}{l}\text { Hospital midwife } \\
(n=127)\end{array}$} & \multicolumn{2}{|c|}{$\begin{array}{l}\text { Other } \\
(n=67)\end{array}$} & \multicolumn{2}{|c|}{$\begin{array}{l}\text { Total } \\
(n=439)\end{array}$} \\
\hline & $\mathbf{n}$ & $\%$ & $\mathbf{n}$ & $\%$ & $\mathbf{n}$ & $\%$ & $\mathbf{n}$ & $\%$ \\
\hline Moved addresses due to unaffordability of house rental & 152 & 62.0 & 101 & 79.5 & 52 & 77.6 & 305 & 69.5 \\
\hline Staying with whānau/friends & 167 & 68.2 & 114 & 89.9 & 60 & 89.6 & 341 & 77.7 \\
\hline Overcrowded housing & 139 & 56.7 & 96 & 75.6 & 54 & 80.6 & 289 & 65.8 \\
\hline Became homeless during pregnancy & 86 & 35.1 & 82 & 64.6 & 34 & 50.7 & 202 & 46.0 \\
\hline Became homeless after the birth & 25 & 10.2 & 43 & 33.9 & 21 & 31.3 & 89 & 20.3 \\
\hline Living in emergency accommodation at any point & 111 & 45.3 & 93 & 73.2 & 43 & 64.2 & 247 & 56.3 \\
\hline Living in a garage & 54 & 22.0 & 53 & 41.7 & 31 & 46.3 & 138 & 31.4 \\
\hline Living in a car & 17 & 6.9 & 36 & 28.3 & 19 & 28.4 & 72 & 16.4 \\
\hline
\end{tabular}

\section{Table 3. Midwives providing care to women experiencing} heating and weatherproofing problems

$\begin{array}{lll}\begin{array}{l}\text { Question: To your knowledge, have women in your } \\ \text { care experienced any of the following problems } \\ \text { with their accommodation during the last 12 months }\end{array} & \begin{array}{l}\text { Caseloading } \\ \text { or LMC } \\ \text { midwife }\end{array} \\ \begin{array}{l}\text { Heating/weatherproofing problem } \\ \text { Inadequate heating facilities in the home }\end{array} & 154 & 62.9 \\ \text { Unable to afford to heat the home } & 140 & 57.1 \\ \text { House feels cold during midwifery visits } & 173 & 70.6 \\ \text { House is damp } & 168 & 68.6 \\ \text { House has mould } & 147 & 60.0 \\ \text { House is not weatherproof } & 59 & 24.1 \\ \text { Inadequate cooking facilities in the home } & 40 & 16.3\end{array}$

women who were unable to afford to heat the home. A high proportion of respondents reported that they had undertaken visits in houses that felt cold (70.6\%), damp (68.6\%) and/ or mouldy $(60.0 \%)$. Smaller proportions reported inadequate cooking facilities $(16.3 \%)$ or poor weatherproofing $(24.1 \%)$.

\section{Comments from midwives:}

... living in rental accommodation with inadequate heating, too much damp, mould growing on walls. Landlords unwilling to fix these issues.

Living in cold/damp/mouldy houses as no other option.

A very real problem, living in old buses and farm sheds with no running water or power.

\section{Income, essential items and food insecurity}

Survey respondents were asked if they had provided midwifery care to women who had experienced issues due to lack of money, such as having transport difficulties, communication difficulties, or being unable to meet the costs of co-payments for health care - for example, general practitioner visits, prescriptions and/or pregnancy ultrasound.

The majority of the respondents identified that they had had such experiences (Table 4), with $82.4 \%$ indicating that they had cared for women who had transport difficulties due to lack of money, $81 \%$ had cared for women who had problems with communication due to no availability of phone or no credit on the phone. Over two thirds of the midwives reported that the women they provided care to were unable to meet the costs of co-payments for health care $(68.2 \%)$ with a further $51.7 \%$ identifying that women in their care were unable to afford essential items for themselves or their baby $(58.8 \%)$. The majority of midwives reported the need to provide advocacy for benefit issues $(61.3 \%)$ and needing to refer to other agencies $(62.9 \%)$.

\section{Comments from midwives:}

Challenging when social services have reports of concern for non-attendance or lack of contact when it's usually lack of transport or money for phones that causes it. Also interagency collaboration could be lots better. Midwives can be left out of discussions (social workers /cyfs [now Oranga Tamariki Ministry for Children]) which can put us in positions of risk and also we have additional information that would be important to the conversations.

Table 4. Midwives providing care for women experiencing income and food insecurity issues

\begin{tabular}{|c|c|c|c|c|c|c|c|c|}
\hline \multirow{2}{*}{$\begin{array}{l}\text { Question: Have women in your care experienced any of the following } \\
\text { during the last } 12 \text { months? } \\
\text { Issue related to lack of money }\end{array}$} & \multicolumn{2}{|c|}{$\begin{array}{l}\text { Caseloading or } \\
\text { LMC midwife }\end{array}$} & \multicolumn{2}{|c|}{ Hospital midwife } & \multicolumn{2}{|c|}{ Other } & \multicolumn{2}{|c|}{ Total } \\
\hline & $\mathbf{n}$ & $\%$ & $\mathbf{n}$ & $\%$ & $\mathbf{n}$ & $\%$ & $\mathbf{n}$ & $\%$ \\
\hline Transport difficulties due to cost or lack of money & 179 & 73.1 & 119 & 93.7 & 62 & 92.5 & 360 & 82.4 \\
\hline Requiring food parcels & 100 & 40.8 & 79 & 62.2 & 52 & 77.6 & 231 & 52.9 \\
\hline Problems with communication (no phone or no credit on phone) & 181 & 73.9 & 113 & 89.0 & 60 & 89.6 & 354 & 81.0 \\
\hline Requiring some advocacy with benefit issues & 123 & 50.2 & 92 & 72.4 & 53 & 79.1 & 268 & 61.3 \\
\hline Inability to meet the costs of co-payments for health care & 149 & 60.8 & 96 & 75.6 & 53 & 79.1 & 298 & 68.2 \\
\hline Unable to afford essential items for the woman & 97 & 39.6 & 83 & 65.4 & 46 & 68.7 & 226 & 51.7 \\
\hline Unable to afford essential items for the baby & 108 & 44.1 & 100 & 78.7 & 49 & 73.1 & 257 & 58.8 \\
\hline Requiring referrals to other agencies & 118 & 48.2 & 103 & 81.1 & 54 & 80.6 & 275 & 62.9 \\
\hline
\end{tabular}


Remaining in unaffordable rental and therefore unable to afford to register or warrant car, resulting in fines that cannot be paid and the ongoing consequences of this. Also unable to afford prescriptions or healthy food due to unaffordable housing costs.

\section{Social issues}

The respondents identified that they had worked with women who had experienced family violence (72\%), a need for women's refuge $(44 \%)$, and care and protection issues $(64.7 \%)$ in the previous 12 months. They also identified caring for women with excessive alcohol consumption (43.3\%) and drug taking (62.2\%), along with smoking $(78.8 \%)$, with a further $77.9 \%$ reporting caring for women with mental health concerns.

\section{Comments from midwives:}

Need more support for moderate mental health problems so they don't get bigger. Women motivated to changelhelp themselves more during pregnancy but opportunities missed by not fitting the strict criteria for referral.

I am very worried about the use of methamphetamine and synthetic cannabis in pregnancy which seems to be an increasing problem in my area.

I think that the use of meth $(P)$ is a massive issue that we aren't fully aware of the extent of.

\section{Impact on the midwife and midwifery care}

We asked the midwifery participants, "How does caring for women living in poverty, or with social complexities, impact on your midwifery care?" The question differed depending on the role of the midwife due to the differing nature of care provision.

\section{Impact on community/caseloading midwives}

Table 5 illustrates the impact on the work of community LMC/ caseloading midwives, with $65.4 \%$ identifying the need for longer appointments, more referrals to other agencies (71\%), and more time needed for that liaison (66.5\%). A further $64.9 \%$ reported difficulty accessing the woman to provide care and $41.2 \%$ identified concerns about their own personal safety whilst providing care. Midwives own emotional health was affected by providing care to women living with the effects of socio-economic disadvantage, with 59.4\% declaring an impact, $64.1 \%$ identifying feelings of inadequacy in terms of the available support options for the woman, and $70.2 \%$ agreeing that they worried about the woman's wellbeing.

\begin{tabular}{lll}
$\begin{array}{l}\text { Table 5. Impact on midwifery work for caseloading or } \\
\text { LMC midwives }\end{array}$ & $\mathbf{n}$ & $\%$ \\
Impact & 158 & 65.4 \\
Need for longer appointments & 159 & 64.9 \\
Difficulty accessing women to provide care & 143 & 58.4 \\
Impact on their personal emotional health & 157 & 64.1 \\
Feelings of inadequacy & 101 & 41.2 \\
Situations where own safety compromised & 174 & 71.0 \\
Requiring referrals to other agencies & 163 & 66.5 \\
More time needed for liaison & 172 & 70.2 \\
\hline Worrying about women's wellbeing & &
\end{tabular}

\section{Impact on hospital midwives}

There were similar levels of concern identified by the hospital midwives (Table 6). A high proportion of the hospital midwives (89.6\%) and educators/managers/others (92.5\%) identified that the woman needed additional care, and that the woman needed more support for parenting (hospital midwives $84.4 \%$; educators/ managers/others $82.5 \%$ ). Midwives also reported women needed referrals to other agencies (hospital midwives $89.0 \%$; educators/ managers/others $92.5 \%$ ), and more time was needed for liaison with those services (hospital midwives $76.6 \%$; educators/managers/ others $87.5 \%$ ). Providing care also influenced these midwives' emotional health, with $66.2 \%$ of hospital midwives and $72.5 \%$ of educators/managers/others identifying an impact on their own personal emotional health; feelings of inadequacy of available options for the woman (hospital midwives 69.5\%; educators/ managers/others $77.5 \%$ ); and worry for the woman's wellbeing (hospital midwives 85.1\%; educators/managers/others 95.0\%).

\section{DISCUSSION}

This study aimed to capture midwives' perspectives about women experiencing socio-economic disadvantage and maternity care. The midwives who participated in the survey reported that they provide care for women with a wide range of issues relating to socio-economic disadvantage. The results provide insight into the prevalence of maternal socio-economic disparities that affect maternal health and wellbeing during childbearing, which consequently also impact on infants' health.

\section{The pre-requisites for health}

Our findings indicate that there are women in Aotearoa New Zealand who do not have the appropriate pre-requisites for health. The World Health Organization emphasises that health is a human right that can only be achieved if the pre-requisites are present.

\begin{tabular}{|c|c|c|c|c|}
\hline \multirow[t]{2}{*}{ Impact } & \multicolumn{2}{|c|}{ Hospital midwife } & \multicolumn{2}{|c|}{ Educator/manager/other } \\
\hline & $\mathbf{n}$ & $\%$ & $\mathbf{n}$ & $\%$ \\
\hline The woman needs additional midwifery care to support her wellbeing & 138 & 89.6 & 37 & 92.5 \\
\hline The woman needs more support in her parenting & 130 & 84.4 & 33 & 82.5 \\
\hline Impact on their personal emotional health & 102 & 66.2 & 29 & 72.5 \\
\hline Feelings of inadequacy & 107 & 69.5 & 31 & 77.5 \\
\hline Situations where own safety compromised & 86 & 55.8 & 21 & 52.5 \\
\hline Requiring referrals to other agencies & 137 & 89.0 & 37 & 92.5 \\
\hline More time needed for liaison & 118 & 76.6 & 35 & 87.5 \\
\hline Worrying about the woman's wellbeing & 131 & 85.1 & 38 & 95.0 \\
\hline
\end{tabular}


These fundamental requirements for health include: peace, shelter, education, food, income, a stable eco-system, sustainable resources, social justice and equity (World Health Organization, 1986). Inequalities in socio-economic conditions throughout the life course are considered to be responsible for many inequalities in health (Marmot, 2017a), and action to improve health and reduce inequalities does not simply depend on individual changes, because the ability to change is constrained by social circumstances (Marmot, 2017b).

The findings of this survey showed that midwives are providing care to women who often do not have adequate shelter or sufficient income for food and other costs related to their pregnancy and following the birth of their baby. This lack of the pre-requisites to achieve health is concerning and suggests that equality and optimal health outcomes for mothers and babies will not be achieved without concentrated efforts on many fronts. It is therefore unsurprising that the women in lower socio-economic groups have higher rates of maternal mortality and perinatal mortality, i.e. stillbirth and neonatal death (Perinatal and Maternal Mortality Review Committee, 2019). Optimising outcomes for women during childbirth is an important goal but arguably can only succeed if the social determinants of health are identified and adequately addressed for pregnant women in Aotearoa New Zealand. Concerted cross-governmental efforts will be required to address maternal socio-economic disadvantage. If child wellbeing is to be achieved, maternal pre-requisites for health are essential goals.

\section{Transience and moving homes}

A large proportion of midwives reported providing care to women who were homeless, staying with whānau (family), or who had to move during their maternity care. Moving houses is considered one of the five most stressful life events and moving during pregnancy results in poorer health than not moving (Tunstall, Pickett, \& Johnsen, 2010). The Growing Up in New Zealand study found that $45.3 \%$ of families had moved at least once between the birth of a child and that child reaching two years of age (Morton, Atatoa Carr et al., 2014). When Tunstall et al. (2010) used cross sectional data for the 18,197 families in the UK Millennium Cohort, they found that families that move during pregnancy, due to negative circumstances, had worse self-rated health and more depression among the mothers, lower birth weight of the babies and a higher risk of accidents among the infants. There is a growing body of literature that links high levels of stress during pregnancy with less favourable or adverse outcomes in the developing baby (Horsch et al., 2017; Kingsbury et al., 2016; Phelan et al., 2015).

\section{Poor quality housing}

Cold, damp and mouldy homes were identified as an issue by many of the caseload/LMC community midwives who visit women's homes during pregnancy and/or following the birth of the baby.

Fuel poverty is a term that identifies the inability to heat the home to an adequate temperature at a reasonable cost and is recognised as a significant issue (Grey et al., 2017). Living in cold, damp conditions can have a negative effect on the physical and mental health of the occupants and can exacerbate existing medical conditions such as respiratory or cardiovascular problems (Grey et al., 2017). Other effects of fuel poverty amongst adults are higher levels of minor illness, such as colds and flu, and poorer mental health (Marmot Review Team, 2011). Dampness and mould are also associated with increased rates of respiratory infections and bronchitis in infants (Fisk et al., 2010). Ingham et al. (2019) described housing as a risk factor for childhood respiratory illness and found a dose response association between housing quality, measured related to damp and mould, and hospital admission for young children. Mason, Lindberg, Read and Borman (2018) also found that damp, mouldy housing had a major effect on children's health in their Aotearoa New Zealand study, with approximately 500 children admitted to hospital annually due to asthma.

This association between poor quality housing and poor health is well documented, and has been an ongoing concern for centuries, with those living in impoverished conditions being over-represented in poorer health outcomes (Kreiger \& Higgins, 2002). Poor quality housing affects multiple aspects of health and wellbeing and is particularly problematic for infants and children. It is promising that the New Zealand Government has committed to meeting its human rights commitment through the United Nations (UN) Agenda for Sustainable Development with the aim to provide safe, affordable and adequate housing for all by 2030 (New Zealand Human Rights Commission and $\mathrm{He}$ Kainga Oranga/Housing and Health Research Programme, 2016). The lack of affordable housing has been identified by the current government as a priority action issue, with pregnant women and their families currently prioritised in the Healthy Homes Initiative (Pierse, White, \& Riggs, 2019).

\section{Health and lifestyle}

The period of time when they are receiving maternity care is often considered a time for optimising women's health through consistent public health messaging at a crucial life/developmental stage (including smoking cessation, alcohol free pregnancy, healthy food, being active, healthy weight gain and family violence screening).

Healthy eating requires access to healthy affordable food, yet for women on low incomes this can be problematic. A Canadian resource identified that women often understand the need to eat healthy food during pregnancy but are unable to do so due to a lack of means (Best start: Ontario's Maternal Newborn and Early Child Development Resource Centre, n.d.). In Aotearoa New Zealand, Morton, Grant et al. (2014) found that most pregnant women do not follow the current nutritional guidelines for pregnancy, with only $3 \%$ meeting the recommendations for the four identified food groups. Food insecurity is a major barrier to a healthy pregnancy, with food purchase often less a priority than rent and/or heating (Abrahams, Lund, Field, \& Honikman, 2018; Raven \& StewartWithers, 2019; van den Heuvel \& Birken, 2018).

Living in deprived circumstances increases the risk of depression and stress (Wilkinson \& Marmot, 2003). When women are living in circumstances, where they are continually anxious, worried and stressed and have little control over work and income, the use of alcohol, drugs and tobacco can be a way of coping with that stress and anxiety (Wilkinson \& Marmot, 2003). For women living with socio-economic disadvantage, there are often competing priorities and multiple barriers. For the health carer, assessing women's needs and supporting them to identify and meet their priorities are often more important than providing a public health message that will remain unheeded. Women have identified that empathic interaction from someone who listens, does not pass judgement and does not shame or blame is important to them (Best start: Ontario's Maternal Newborn and Early Child Development Resource Centre, n.d.; Ebert, Bellchambers, Ferguson, \& Browne, 2014; McLeish \& Redshaw, 2019). A holistic approach is considered optimal; one which connects and refers to other providers and services. This would be similar to the Whānau Ora approach for 
Māori, an approach which seeks to put whānau and families in control of services (New Zealand Government, 2020).This is especially important for Māori women who are over-represented within the groups living in the most deprived neighbourhoods (Ministry of Health, 2019). The approach may also be useful for other ethnic groups who are socially disadvantaged. Solutions that support all women living in poverty are urgently needed.

\section{Impact on midwives and midwifery care}

The vast majority of Aotearoa New Zealand women engage with midwives for their maternity care (Ministry of Health, 2019). Women living in deprived quintiles are more likely to choose a midwife as their LMC. However, for women with low incomes, barriers due to social, housing and income issues can cause increased, and often undisclosed, health needs and social service delivery gaps. Midwives are one of the few health professionals who visit the woman and her family in the woman's home. This enables the midwife to understand the reality of the woman's life and the difficulties and issues she may be facing in relation to accessing physical and social support.

Midwives, whether working in hospital or in the community, identified that there was an impact for them when working with women with low incomes. Women with complex social and/or poverty related concerns frequently required more time and longer appointments with midwives. This was so that the woman's issues could be fully discussed and strategies identified to support her and her family. It is only by taking the time to do this that midwives can then identify and discuss harm reduction strategies, and provide health information and parenting support. A number of midwives reported the need for referral (with often multiple referrals) and liaison with other agencies. Doing this is time consuming and requires knowledge of available local community services. For midwives working in the community specifically, there were often difficulties accessing the woman (due to transience) to provide maternity care, and a need for more home visits to provide that care during pregnancy as well as during the postpartum. Our findings resonate with those of Griffiths (2002) in her qualitative study involving eight Aotearoa New Zealand midwives. She found that the midwives she interviewed 'stayed involved' because 'the need seems so huge' and that women were sometimes wary of forming relationships, which were necessary to ensure support and to provide education on improving health and parenting. These midwives also identified that issues were often not related to maternity care but, nevertheless, required the midwives' time and support of the family in order to optimise the woman's and her baby's health. They also reported that women were often dealing with different forms of abuse (physical violence, drug and alcohol addiction, etc.) and required additional time for liaison with the appropriate government agencies and community services.

Providing care to women in these circumstances also affected the midwife's emotional health, with midwives in this study admitting personal worry about the woman's wellbeing, feelings of inadequacy, and there were situations where the midwives themselves felt their personal safety was compromised. This finding echoes those of the midwives in Griffiths' (2002) study who described emotional conflict, needing a network of support to help them emotionally, and needing to ensure their own personal physical safety.

Providing maternity care to women living in socio-economic disadvantage is challenging on many levels. It requires additional resources both for women and their families and for the health professionals providing that care. At present the workload involved in supporting women living in impoverished circumstances does not attract additional funding. Any new funding model proposed by the New Zealand Government will need to identify, recognise and reimburse community midwives appropriately when they work with women living in difficult and/or impoverished circumstances. Hospital maternity services also need to recognise the additional resources required by women, the impact on midwives working with these women, and the need to ensure additional staffing levels.

This study strongly suggests that during pregnancy, while all women need dedicated time and support to deal with the issues they face during this major life event, the economically deprived need significantly more time and support. Midwives are the health professionals providing physical and emotional support and require improved resources and support themselves.

\section{STRENGTHS AND LIMITATIONS}

This is the first survey exploring maternal socio-economic disadvantage from a midwifery perspective within the Aotearoa New Zealand context. This study has enabled us to explore the depth of midwifery concern about the impact of socio-economic disadvantage on women, as well as the impact on the midwives themselves. Survey methodology is limited by lack of nuance and cannot avoid eliciting detailed responses and answers from those who hold strong opinions on the subject matter. The survey responses are not generalisable but do provide a snapshot of the socio-economic disadvantage-related issues women are experiencing and the effect of these on the work of our respondent midwives.

\section{CONCLUSION}

This study has demonstrated the complex demanding nature of the midwifery care being provided to women and families living with socio-economic disadvantage. This cohort of midwives reports providing care to pregnant women who are experiencing homelessness, transience, and/or poor quality accommodation during their pregnancy and following the birth. During pregnancy women are also often experiencing material deprivation and many have insufficient funds for food items, transport and communication. They are frequently unable to afford the costs of co-payments for maternity health care and they often cannot afford the essential items they need for themselves and/or their baby. There is need for urgent action to support pregnant women living with socio-economic disadvantage. A good start to life for babies and children means supporting and improving circumstances for women during pregnancy and birth.

Midwives engage with a diverse group of women and families within society, many of whom are vulnerable or experience chaotic or difficult social circumstances. These women and their families often fall through the gaps in care provision for a variety of reasons. The midwives' role is to provide information, support and healthcare for the woman for her pregnancy, birth and early parenting. Unfortunately, women who are living in these difficult circumstances require more than midwifery care; they also need social, income, housing and sometimes legal support. Although midwives are ideally placed to navigate, and refer the woman to, these other services - when they are available and accessible doing so takes time and deserves recognition along with funding support. At present, and in order to protect women and their babies, midwives are stepping into this gap and referring, liaising and advocating with a variety of agencies. This work needs to be identified, recognised, valued and better supported. 


\section{ACKNOWLEDGEMENTS AND CONFLICT OF INTEREST DISCLOSURE}

We would like to thank all the midwives who took the time to complete our survey.

The authors state they had no conflict of interests when undertaking this study.

Affiliation: Maternity Equity Action (MEA) is an organisation that aims to explore the prevalence and impact of poverty on women during childbirth. It is a nationwide advocacy group which seeks to collate consensus among health professionals and then advocate for policies which support this consensus.

Key messages
- Midwives work with many
women and families living with
socio-economic disadvantage.
- This study explored the effect of
socio-economic disadvantage
from a midwife's perspective.
Providing maternity care
to women living with socio-
economic disadvantage is
challenging; it requires more
time, more referral to other
agencies and more advocacy
from midwives.

\section{REFERENCES:}

Abrahams, Z., Lund, C., Field, S., \& Honikman, S. (2018). Factors associated with household food insecurity and depression in pregnant South African women from a low socio-economic setting: a crosssectional study. Soc Psychiatry Psychiatr Epidemiol, 53(4), 363-372. https://doi.org/10.1007/s00127-018-1497-y

Asher, I., \& St John, S. (2016). Child poverty and health in New Zealand. Retrieved from https://thepolicyobservatory.aut.ac.nz/

Best start: Ontario's Maternal Newborn and Early Child Development Resource Centre. (2003). The Impact Of Poverty On Pregnant Women: A guide to program managers. Retrieved from https://www.beststart.org/ Best start: Ontario's Maternal Newborn and Early Child Development Resource Centre. (n.d.). Reducing the Impact: working with pregnant women who live in difficult life situations. Retrieved from https://www. beststart.org/

Braveman, P.A., Cubbin, C., Egerter, S., Williams, D.R., \& Pamuk, E. (2010). Socioeconomic disparities in health in the United States: what the patterns tell us. Am J Public Health, 100 Suppl 1, S186-196. https:// doi.org/10.2105/AJPH.2009.166082

Carter, K.N., Kruse, K., Blakely, T., \& Collings, S. (2011). The association of food security with psychological distress in New Zealand and any gender differences. Soc Sci Med, 72(9), 1463-1471. https://doi. org/10.1016/j.socscimed.2011.03.009

Clark, A., D'Ambrosio, C., \& Barazzetta, M. (2019). Childhood circumstances and young adult outcomes: the role of mothers' financial problems. Retrieved from https://ideas.repec.org/p/cep/cepdps/dp1609.html Department of the Prime Minister and Cabinet. (2018). Legislating to Drive Action to Reduce Child Poverty. Retrieved from https://dpmc.govt. $\mathrm{nz} /$ sites/default/files/2018-03/doc-06-cbc-paper-legislating-to-driveaction-to-reduce-child-poverty.pdf
Ebert, L., Bellchambers, H., Ferguson, A., \& Browne, J. (2014). Socially disadvantaged women's views of barriers to feeling safe to engage in decision-making in maternity care. Women Birth, 27(2), 132-137. https://doi.org/10.1016/j.wombi.2013.11.003

Fisk, W.J., Eliseeva, E.A., \& Mendell, M.J. (2010). Association of residential dampness and mold with respiratory tract infections and bronchitis: a meta-analysis. Environ Health, 9, 72. https://doi. org/10.1186/1476-069X-9-72

Foster, H.M.E., Celis-Morales, C.A., Nicholl, B.I., PetermannRocha, F., Pell, J.P., Gill, J.M.R., ... Mair, F.S. (2018). The effect of socioeconomic deprivation on the association between an extended measurement of unhealthy lifestyle factors and health outcomes: a prospective analysis of the UK Biobank cohort. The Lancet Public Health, 3(12), e576-e585. https://doi.org/10.1016/s2468-2667(18)30200-7 Grey, C.N.B., Schmieder-Gaite, T., Jiang, S., Nascimento, C., \& Poortinga, W. (2017). Cold homes, fuel poverty and energy efficiency improvements: A longitudinal focus group approach. Indoor Built Environ, 26(7), 902-913. https://doi.org/10.1177/1420326X17703450 Griffiths, C. (2002). Staying involved 'because the need seems so huge'. (Unpublished master's thesis). Massey University, Palmerston North, New Zealand. Retrieved from https://mro.massey.ac.nz/xmlui/ handle/10179/7239?show=full

Horsch, A., Gilbert, L., Lanzi, S., Kang, J.S., Vial, Y., \& Puder, J. (2017). Associations between maternal stress during pregnancy and obstetric and neonatal outcomes. Psychoneuroendocrinology, 83, 28. https://doi.org/10.1016/j.psyneuen.2017.07.313

Ingham, T., Keall, M., Jones, B., Aldridge, D.R.T., Dowell, A.C., Davies, C., ... Howden-Chapman, P. (2019). Damp mouldy housing and early childhood hospital admissions for acute respiratory infection: a case control study. Thorax, 74(9), 849-857. https://doi.org/10.1136/ thoraxjnl-2018-212979

Katz, J., Crean, H.F., Cerulli, C., \& Poleshuck, E.L. (2018). Material Hardship and Mental Health Symptoms Among a Predominantly Low Income Sample of Pregnant Women Seeking Prenatal Care. Matern Child Health J, 22(9), 1360-1367. https://doi.org/10.1007/s10995-0182518-x

Kelly, A., Denning-Kemp, G., Geiringer, K., Abdulhamid, A., Albabtain, A., Beard, M., ... Baker, M. (2013). Exposure to harmful housing conditions is common in children admitted to Wellington Hospital. The New Zealand Medical Journal, 126(1387), 108-126.

Kingsbury, M., Weeks, M., MacKinnon, N., Evans, J., Mahedy, L., Dykxhoorn, J., \& Colman, I. (2016). Stressful Life Events During Pregnancy and Offspring Depression: Evidence From a Prospective Cohort Study. Journal of the American Academy of Child \& Adolescent Psychiatry, 55(8), 709-716.e702. https://doi.org/10.1016/j. jaac.2016.05.014

Kreiger, J., \& Higgins, D. (2002). Housing and Health: Time Again for Public Health Action. American Journal of Public Health, 92, 758-768.

Larson, C. (2007). Poverty During Pregnancy: Its effects on child health outcomes. Paediatric Child Health, 12(8), 673-677.

Marmot, M. (2017a). Closing the health gap. Scand J Public Health, 45(7), 723-731. https://doi.org/10.1177/1403494817717433

Marmot, M. (2017b). The health gap: Doctors and the social determinants of health. Scand J Public Health, 45(7), 686-693. https:// doi.org/10.1177/1403494817717448

Marmot Review Team. (2011). The Health Impacts of Cold Homes and Fuel Poverty. Retrieved from http://www.instituteofhealthequity.org/ Mason, K., Lindberg, K., Read, D., \& Borman, B. (2018). The Importance of Using Public Health Impact Criteria to Develop Environmental Health Indicators: The Example of the Indoor Environment in New Zealand. Int J Environ Res Public Health, 15(8). https://doi.org/10.3390/ijerph15081786

McLeish, J., \& Redshaw, M. (2019). Maternity experiences of mothers with multiple disadvantages in England: A qualitative study. Women and Birth, 32(2), 178-184. https://doi.org/10.1016/j.wombi.2018.05.009 Ministry of Health. (2018). Social, Emotional and Behavioural Difficulties in New Zealand Children: Summary of findings. Retrieved from: https:// www.health.govt.nz/publication/social-emotional-and-behaviouraldifficulties-new-zealand-children-new-zealand-health-survey

Ministry of Health. (2019). Report on Maternity 2017. Retrieved from: https://www.health.govt.nz/publication/report-maternity-2017

Moafi, F., Kazemi, F., Samiei Siboni, F., \& Alimoradi, Z. (2018). The relationship between food security and quality of life among pregnant women. BMC Pregnancy Childbirth, 18(1), 319. https://doi.org/10.1186/ s12884-018-1947-2 
Morton, S.M., Grant, C.C., Wall, C.R., Atatoan Carr, P.E., Bandara, D.K., Schmidt, J.M., . . . Camargo, C.A., Jr. (2014). Adherence to nutritional guidelines in pregnancy: evidence from the Growing $U p$ in New Zealand birth cohort study. Public Health Nutr, 17(9), 1919-1929. https://doi.org/10.1017/S1368980014000482

Morton, S.M.B., Atatoa Carr, P.E., Grant, C.C., Berry, S.D., Bandara, D.K., Mohal, J., Tricker, P.J., . . . Wall, C.R. (2014). Growing up in New Zealand: A longitudinal study of New Zealand children and their families. Now we are Two: Describing our first 1000 days. Retrieved from https://www.growingup.co.nz/

New Zealand Government. (2020). Te Puni Kokiri: Ministry of Maori Development. Retrieved from https://www.govt.nz/organisations/tepuni-kokiri/

New Zealand Human Rights Commission and He Kainga Oranga/ Housing and Health Research Programme. (2016). Inadequate Housing in New Zealand and its impact on children: Thematic snapshot report to the United Nations Committee on the rights of the Child. Retrieved from Wellington:

Perinatal and Maternal Mortality Review Committee. (2019). Thirteenth Annual report of the Perinatal and Maternal Mortality Review committee: Reporting mortality and morbidity 2017. Retrieved from https://www. hqsc.govt.nz/our-programmes/mrc/pmmrc/publications-and-resources/ publication/3823/

Phelan, A. L., DiBenedetto, M. R., Paul, I. M., Zhu, J., \& Kjerulff, K. H. (2015). Psychosocial Stress During First Pregnancy Predicts Infant Health Outcomes in the First Postnatal Year. Matern Child Health J, 19(12), 2587-2597. doi:10.1007/s10995-015-1777-z

Pierse, N., White, M., \& Riggs, L. (2019). Healthy Homes Initiative Outcomes Evaluation Service: Initial analysis of health outcomes (Interim report). Retrieved from https://www.health.govt.nz/system/files/ documents/publications/healthy-homes-initiative-outcomes-evaluationinterim-report-18sept2019.pdf

Priday, A. (2018). A Daunting Journey: Accessing a Lead Maternity Care Midwife. (Unpublished master's thesis). Auckland University of Technology, New Zealand.

Raven, B., \& Stewart-Withers, R. (2019). Using critical discourse analysis and the concept of food security to understand pregnant women's nutrition in Aotearoa/New Zealand. New Zealand College of Midwives Journal, 55, 35-43. Retrieved from https://portal.midwife.org. $\mathrm{nz} /$ research-article/1412

Stats NZ. (2019). Measuring child poverty: Material hardship. Retrieved from www.stats.govt.nz

Tunstall, H., Pickett, K., \& Johnsen, S. (2010). Residential mobility in the UK during pregnancy and infancy: Are pregnant women, new mothers and infants 'unhealthy migrants'? Social Science \& Medicine, 71(4), 786-798. https://doi.org/10.1016/j.socscimed.2010.04.013 van den Heuvel, M., \& Birken, C. (2018). Food insecurity and breastfeeding. CMAJ, 190(11), E310-E311. https://doi.org/10.1503/ cmaj.180167

Vettore, M., Gama, S., Lamarca, G., Schilithz, A., \& Leal, M. (2010). Housing conditions as a social determinant of low birthweight and preterm low birthweight. Revista de Saude Publica, 44(6), 1021-1031. Wilkinson, R., \& Marmot, M. (Eds.). (2003). Social Determinant of Health: The Solid Facts (2nd ed.). Denmark: The World Health Organization Library.

World Health Organization. (1986). The Ottawa Charter for Health Promotion. Retrieved from https://www.who.int/healthpromotion/ conferences/previous/ottawa/en/

\section{Accepted for Publication September 2020}

Dixon, L., Neely, E., Eddy, A., Raven, B., \& Bartle, C. (2020). Maternal socio-economic disadvantage in Aotearoa New Zealand and the impact on midwifery care. New Zealand College of Midwives Journal, 56, 26-34. https://doi.org/10.12784/nzcomjn156.2020.4.26-34 